\title{
Caracterização Microbiológica de Derivados Lácteos Comercializados Na Cidade de Pombal PB
}

\author{
Ana Flávia de Melo Cândido (I), Willianny de Medeiros Costa (I), \\ Tiago da Nóbrega Albuquerque (I), Maria do Socorro Araujo \\ Rodrigues (I), Alfredina dos Santos Araújo (I) \\ (I) UFCG - UNIVERSIDADE FEDERAL DE CAMPINA GRANDE (Campus Pombal - Rua Jario \\ Vieira Feitosa, ํㅜ 1770, Bairro dos Pereiros,Pombal-PB)
}

\section{Resumo}

Os derivados lácteos são alimentos com excepcional valor nutritivo e amplamente consumidos pela população em geral, sendo excelente fonte de nutrientes, servindo de meio de cultura para os microrganismos, portanto, suscetíveis a contaminação por distintos agentes microbiológicos, podendo induzir a doenças manifestadas por ação de patógenos ou por suas toxinas. O objetivo do presente estudo foi caracterizar microbiologicamente, amostras de queijo coalho (QC), queijo de manteiga (QM), manteiga da terra (MT) e nata $(\mathrm{N})$ comercializadas informalmente no município de Pombal-PB. As amostras foram coletadas em supermercados da cidade, em embalagens comercializáveis e armazenadas em caixas isotérmicas e encaminhadas ao Laboratório de Microbiologia de Alimentos do Centro Vocacional Tecnológico/ UFCG, campus Pombal. Foram analisadas quanta a presença de coliformes a $45^{\circ} \mathrm{C}$, Staphylococcus spp e Salmonella sp, de acordo com os Métodos de Análise Microbiológica para Alimentos, do Ministério da Agricultura e do Abastecimento (BRASIL, 2003). Das amostras analisadas, $75 \%$ estavam acima dos limites legais para coliformes fecais, sendo que somente a MT não apresentou contaminação. Para a contagem de Staphylococcus spp os resultados encontrados no presente trabalho mostraram um percentual de $75 \%$ das amostras fora dos padrões

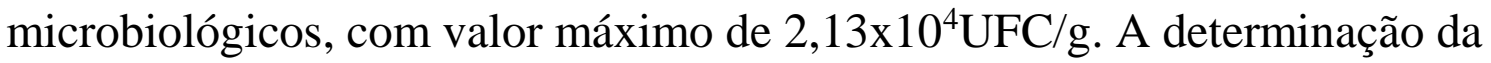
prova de presença/ausência de Salmonella sp, patógeno preocupante, pois

\footnotetext{
Referência:

Ana Flávia de Melo Cândido, Willianny de Medeiros Costa, Tiago da Nóbrega Albuquerque, Maria do Socorro Araujo Rodrigues, Alfredina dos Santos Araújo. Caracterização Microbiológica de Derivados Lácteos Comercializados $\mathrm{Na}$ Cidade de Pombal $\mathrm{Pb}$. In: Anais do 12 Congresso Latinoamericano de Microbiologia e Higiene de Alimentos MICROAL 2014 [= Blucher Food Science Proceedings, num.1, vol.1]. São Paulo: Editora Blucher, 2014. DOI 10.5151/foodsci-microal-237
} 
este microrganismo pode causar toxinfecções alimentares graves, foi detectada presença deste em 50\% das amostras. Os resultados alcançados indicam que os produtores dos derivados lácteos estudados não adotam medidas higiênico-sanitárias adequadas na obtenção e conservação dos seus produtos e que este causam reflexos na qualidade dos mesmos. Sendo assim, esta pesquisa contribuirá fornecendo dados científicos as autoridades regulamentadoras, enxergando a possibilidade da utilização das boas práticas de fabricação, para que assim obtenham-se alimentos seguros.

Palavras-Chave: derivados lácteos, toxinfecções alimentares, fonte de nutrientes.

\section{Agência de Fomento:}

